\title{
Concepts for Small-Scale Testing of Used Nuclear Fuel
}

Fuel Cycle Research \& Development

Prepared for

U.S. Department of Energy Used Fuel Disposition Campaign

Steven C. Marschman, INL Philip L. Winston, INL

Revision 0

September 25, 2015 FCRD-UFD-2015-000767 


\section{DISCLAIMER}

This information was prepared as an account of work sponsored by an agency of the U.S. Government. Neither the U.S. Government nor any agency thereof, nor any of their employees, makes any warranty, expressed or implied, or assumes any legal liability or responsibility for the accuracy, completeness, or usefulness, of any information, apparatus, product, or process disclosed, or represents that its use would not infringe privately owned rights. References herein to any specific commercial product, process, or service by trade name, trade mark, manufacturer, or otherwise, does not necessarily constitute or imply its endorsement, recommendation, or favoring by the U.S. Government or any agency thereof. The views and opinions of authors expressed herein do not necessarily state or reflect those of the U.S. Government or any agency thereof. 
FCRD-UFD-2015-000767

\title{
Concepts for Small-Scale Testing of Used Nuclear Fuel
}

\author{
Steven C. Marschman \\ Philip L. Winston
}

Revision 0

September 25, 2015

\author{
Idaho National Laboratory \\ Idaho Falls, Idaho 83415
}

http://www.inl.gov

Prepared for the

U.S. Department of Energy

Office of Used Nuclear Fuel Disposition Research and Development

Under DOE Idaho Operations Office Contract DE-AC07-05ID14517 
This page intentionally left blank. 


\section{SUMMARY}

This report fulfills the M3 milestone, M3FT-15IN0805023 Small-scale Test Conceptual Design, under Work Package Number FT-15IN080501.

The U.S. Department of Energy Office of Nuclear Energy (DOE-NE), Office of Fuel Cycle Technology, has established the Used Fuel Disposition Campaign (UFDC) to conduct the research and development activities related to storage, transportation, and disposal of used nuclear fuel and high-level radioactive waste. The mission of the UFDC is to identify alternatives and conduct scientific research and technology development to enable storage, transportation and disposal of used nuclear fuel (UNF) and wastes generated by existing and future nuclear fuel cycles. The UFDC Storage and Transportation staffs are responsible for addressing issues regarding the extended or long-term storage of UNF and its subsequent transportation. The near-term objectives of the Storage and Transportation task are to use a science-based approach to develop the technical bases to support the continued safe and secure storage of UNF for extended periods, subsequent retrieval, and transportation.

While low burn-up fuel [that characterized as having a burn-up of less than 45 gigawatt days per metric ton uranium (GWD/MTU)] has been stored for nearly three decades, the storage of high burn-up used fuels ${ }^{\mathrm{a}}$ is more recent. This report documents a concept for a small-scale test involving between one and three Boiling Water Rector (BWR) high burnup (HBU) fuel assemblies. This test would be similar to the DOE funded High Burn-Up (HBU) Confirmatory Data Project to confirm the behavior of used high burn-up fuel under prototypic conditions, only on a smaller scale. The test concept proposed would collect data from fuel stored under prototypic dry storage conditions to mimic, as closely as possible, the conditions HBU UNF experiences during all stages of dry storage: loading, cask drying, inert gas backfilling, and transfer to an Independent Spent Fuel Storage Installation (ISFSI) for multi-year storage.

This report describes the functional requirements for a small-scale test, the types of fuel that could be tested, proposes a method for testing, and provides a preliminary cost estimate for performing such a test. The effort needed to conduct a small-scale test is significant. The estimated cost to establish a single assembly test is $\$ 5550 \mathrm{~K}$. This includes the cost to acquire the fuel, transport it, prepare the test and initiate the test, and perform the initial fuel characterization.

\footnotetext{
a "High burn-up" fuel has a burn-up level at or above approximately 45 gigawatt-days per metric ton of uranium (GWD/MTU).
} 


\section{CONTENTS}

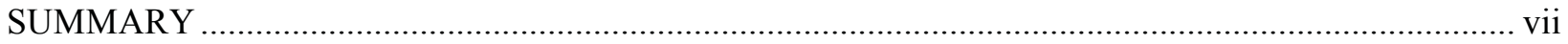

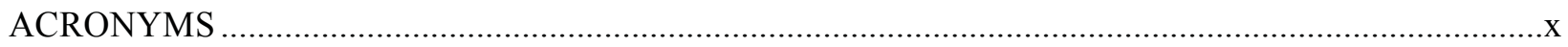

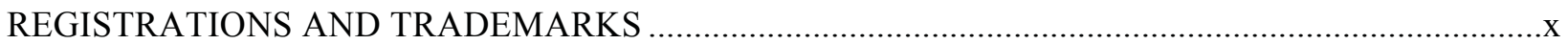

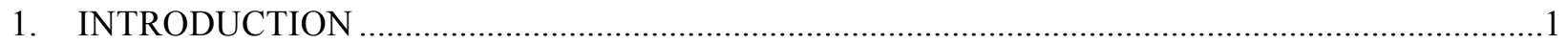

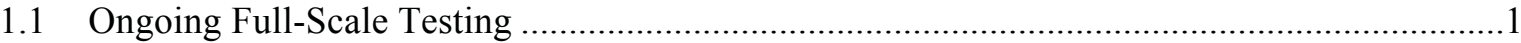

1.2 Gaps Addressed by a Small-Scale Test............................................................................

2. FUNCTIONAL REQUIREMENTS FOR A SMALL-SCALE TEST ..............................................

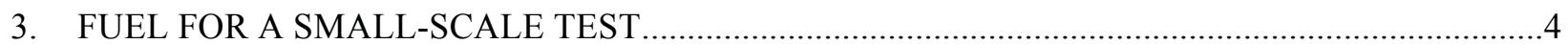

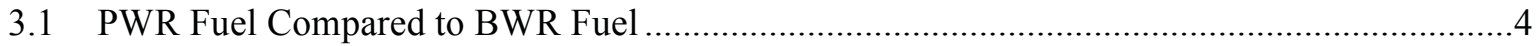

3.2 Typical Characteristics of BWR Fuel Assemblies ...................................................................5

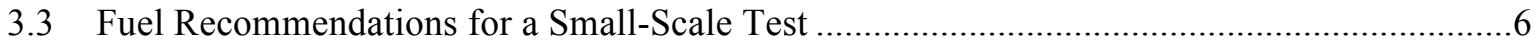

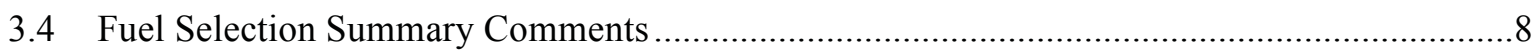

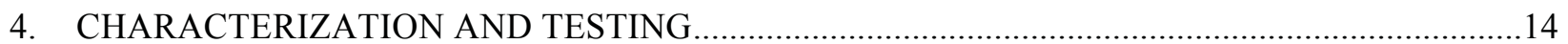

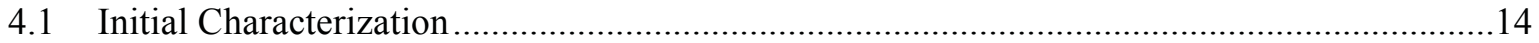

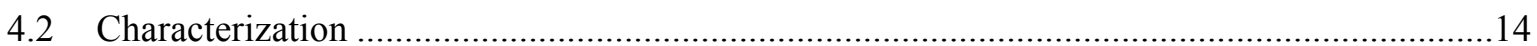

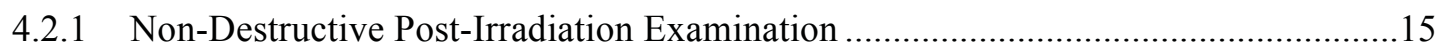

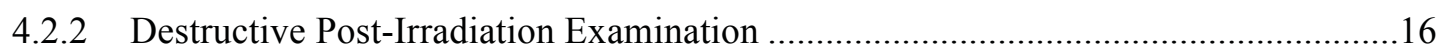

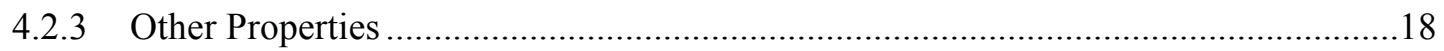

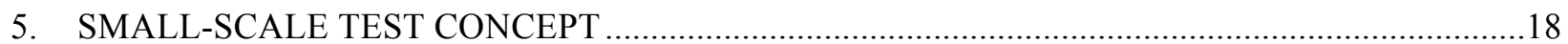

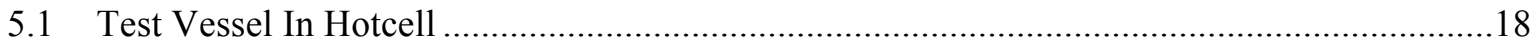

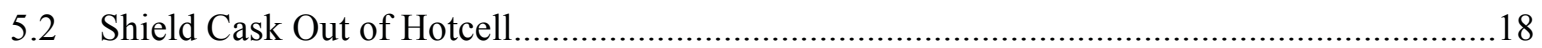

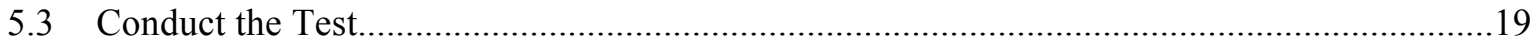

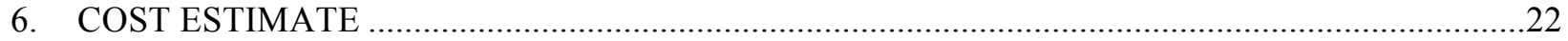

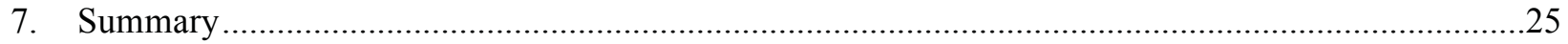

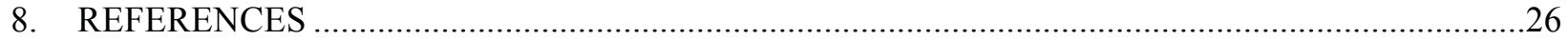




\section{FIGURES}

Figure 1.1. The TN-32B cask holds 32 pressurized water reactor (PWR) fuel assemblies............................ 2

Figure 3.1. Westinghouse SVEA-style 10x10 fuel assembly. (Illustration courtesy of Westinghouse) ............ 9

Figure 3.2. Westinghouse SVEA fuel assembly diagrams showing location of part-length rods and increased diameter rod in the earlier Optima series assemlies. (Illustration courtesy of Westinghouse)

Figure 3.3. The GE14 fuel assembly is illustrated. (Illustration courtesy of GE-Hitachi)

Figure 3.4. The GE14 assembly cross-section shows the locations of part-length rods, tie rods, and water rods. (Illustration courtesy of GE-Hitachi)

Figure 3.5. The AREVA ATRIUM 10XM 10x10 fuel assembly is shown without full-length fuel rods. (Illustration courtesy of AREVA, Inc.).

Figure 3.6. The AREVA ATRIUM-series fuel assembly cross-sections show the locations of partlength rods and the large water channel that is used to support the weight of the fuel assembly. (Illustration courtesy of AREVA, Inc.)

Figure 5.1. The TN-FSV cask being loaded onto its transport cradle.3.2.

Figure 5.2. The TN-FSV illustrated in cross-section. The cask has one of the longest interior spaces of any legal weight transport cask.

Figure 5.3. Two-assembly test concept for the TN-FSV cask 22

\section{TABLES}

Table 6.1 Cost estimate for a small-scale test in FY 2015 dollars 


\section{ACRONYMS}

$\begin{array}{ll}\text { BWR } & \text { boiling water reactor } \\ \text { EPMA } & \text { electron probe micro-analyzer } \\ \text { EPRI } & \text { Electric Power Research Institute } \\ \text { FIB } & \text { Focused Ion Beam } \\ \text { FSV } & \text { Fort St. Vrain } \\ \text { GWD } & \text { gigawatt-day } \\ \text { HBU } & \text { High Burn-Up } \\ \text { HLW } & \text { High Level Waste } \\ \text { INL } & \text { Idaho National Laboratory } \\ \text { ISFSI } & \text { Independent Spent Fuel Storage Installation } \\ \text { LC } & \text { Long Cask } \\ \text { LLW } & \text { Low Level Waste } \\ \text { MTU } & \text { metric ton uranium (or heavy metal) } \\ \text { NRC } & \text { Nuclear Regulatory Commission } \\ \text { ORNL } & \text { Oak Ridge National Laboratory } \\ \text { PNNL } & \text { Pacific Northwest National Laboratory } \\ \text { PWR } & \text { pressurized water reactor } \\ \text { SCC } & \text { stress corrosion cracking } \\ \text { SEM } & \text { scanning electron microscope } \\ \text { SET } & \text { separate effects test } \\ \text { SRNL } & \text { Savannah River National Laboratory } \\ \text { SSC } & \text { Structures, Systems, and Components } \\ \text { SST } & \text { small-scale test } \\ \text { TGA } & \text { thermogravimetric analysis } \\ \text { TN } & \text { (old) TransNuclear, Inc. (now AREVA-TN) } \\ \text { UFDC } & \text { used fuel disposition campaign } \\ \text { UNF } & \text { used nuclear fuel } \\ \text { WDS } & \text { wavelength dispersive spectroscopy } \\ & \end{array}$

\section{REGISTRATIONS AND TRADEMARKS}

Inconel A registered trademark of Special Metals Corporation. 
This page intentionally left blank. 


\section{CONCEPTS FOR SMALL-SCALE TESTING OF USED NUCLEAR FUEL}

\section{INTRODUCTION}

A "small-scale" test is proposed for Boiling Water Reactor (BWR) high burnup (HBU) used nuclear fuel (UNF) under long-term, dry storage conditions. A small-scale test is an integrated test, involving more than one complete fuel rod but less than a full-sized dry storage canister or cask. In this case, a concept is proposed that could use between one and three BWR fuel assemblies. The test would have a duration of at least ten years. The proposed test, similar to the larger HBU Confirmatory Data Project that uses Pressurized Water Reactor (PWR) UNF, would be used to provide confirmatory data regarding HBU BWR UNF.

This report documents the reasons for such a test with applicable functional requirements, a concept for performing the test, and a very preliminary cost estimate.

\subsection{Ongoing Full-Scale Testing}

High burn-up used fuels ${ }^{b}$ have only begun to be placed in dry storage in the past decade or so. As of December 2012, approximately 200 dry storage casks have been loaded with at least some HBU UNF. Furthermore, almost all UNF being discharged from reactors in the U.S. is now high burn-up. Since high burn-up UNF has different mechanical properties than lower burn-up UNF, additional data on high burnup UNF under typical conditions are needed to better understand those differences. The DOE has funded a HBU Confirmatory Data Project to confirm the behavior of high burn-up used fuel under prototypic conditions.[1] The Electric Power Research Institute (EPRI) is leading a project team ${ }^{c}$ to develop and implement the Test Plan to collect this data from a UNF dry storage system containing high burn-up fuel. The Test Plan for this dry storage project outlines the data to be collected; the high burn-up fuel to be included, and the storage system design, procedures, and licensing necessary to implement the Test Plan. This test will be conducted using Pressurized Water Reactor (PWR) HBU UNF from Dominion Virginia Power's North Anna Power Station (North Anna).

To provide data that is most relevant to high burn-up fuel in dry storage, the design of the test storage system must closely mimic real conditions high burn-up UNF experiences during all stages of dry storage: loading, cask drying, inert gas backfilling, and transfer to an Independent Spent Fuel Storage Installation (ISFSI) for multi-year storage.

An AREVA-TN, TN-32B bolted lid cask (Figure 1.1) will be loaded with intact, high burn-up PWR UNF assemblies with four different kinds of cladding at North Anna.

\footnotetext{
b "High burn-up" fuel has a burn-up level at or above approximately 45 gigawatt-days per metric ton of uranium (GWD/MTU).

${ }^{c}$ The EPRI team includes AREVA Federal Services, AREVA-TN, Dominion Virginia Power, AREVA Fuels, and Westinghouse Fuels.
} 


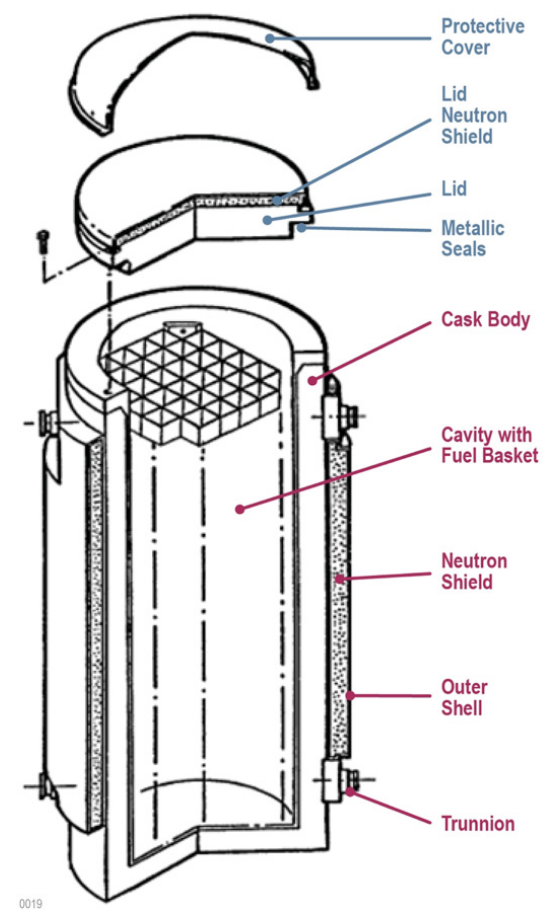

Figure 1.1. The TN-32B cask holds 32 pressurized water reactor (PWR) fuel assemblies.

\subsection{Gaps Addressed by a Small-Scale Test}

The UFDC has issued Gap Analysis to Support Extended Storage of Used Nuclear Fuel[2] that documents the initial gap analysis performed to identify data and modeling needs to develop the desired technical bases to enable the extended storage of UNF. For most SSCs important to safety, additional data are required, often because there are limited data on the new materials used in more modern fuels or dry storage cask systems or because the effects of high burn-up and extended storage are not fully known. Once identified, the program began to establish the methodologies to close those gaps. For several of these "gap closure strategies," a test material must be acquired for use in the strategy's R\&D efforts.

The analysis identified several gaps that require data from UNF samples can provide useful information. These gaps are:

- Subcriticality (burn-up credit and moderator exclusion) - radionuclide inventory in fuel rods

- Stress profiles - mechanical strength of the fuel rod

- Fuel Transfer Options - ensure fuel is handled in a prototypic manner

- Cladding - annealing of radiation damage

- Cladding - H2 effects, reorientation and embrittlement

- Cladding - H2 effects, delayed hydride cracking

- Cladding - oxidation

- Cladding - creep

- Fuel Assembly Hardware - stress corrosion cracking (SCC) of lifting hardware and spacer grids. The data needed to close these gaps will help guide what types of fuel should be acquired by the program.

The report, Gap Prioritization and Closure Plan [3] provides recommendations for the types of testing that may close the gaps. A summary of these data types is below: 
- Subcriticality (burn-up credit and moderator exclusion). Radiochemical assays of fuel rods are recommended along with reactor operational history data. HBU fuel can be analyzed by any of the national laboratory's radiochemical labs. The challenge is to get the detailed design information and reactor operational history. Utilities and vendors consider this data part of their competitive advantage, and are reluctant to release that information.

- Stress Profiles. The testing recommended for this cross-cutting data gap include vibration testing of fuel assemblies and potentially individual fuel rods. If a full fuel assembly is acquired, it may be useful to instrument the shipping cask and truck trailer. Applying instruments (i.e. strain gages) to the fuel is difficult and likely could not be done in the fuel pool prior to loading (attempting to perform a complex operation in a highly regulated work space).

- Cladding. The most important cladding information to be obtained is the mechanical properties at different times. These mechanical properties will vary based on cladding type, burn-up, oxide and crud layer thicknesses, hydride quantity and orientation, radiation damage and annealing, and temperature. Mechanical properties data will be obtained from ring compression tests, expanded plug tests, burst tests, 3- and 4-point bend tests, and creep tests, in addition to traditional hardness, impact, and tensile strength tests. Testing will involve both Separate Effects Tests (SETs) and potentially a Small-Scale Test (SST). Characteristics to be evaluated include annealing of radiation damage, hydride reorientation and embrittlement, delayed hydride cracking, clad oxidation, and cladding creep.

Characterizing these effects will require the largest sample set. It may not be sufficient to simply request fuel that has a certain cladding and fuel burn-up. While the burn-up has become a generalized expression that is used to infer that a fuel with a high burn-up has experienced more operational stress than a low burn-up fuel. However, there is another metric, "fuel duty," that captures estimates of fuel clad corrosion, hydrogen pickup, temperature history and is more descriptive of the clad condition as opposed to the fuel pellet burn-up. [4] It will be important to gather information on proposed fuels to be acquired so the fuel duty can be calculated. This can be done by a utility or by the UFDC (EPRI methods that are used are described in [4]). The higher the fuel duty, the higher the clad corrosion and fission gas release. It would be useful to acquire fuel rods with a range of fuel duty values, however, if that is not possible, then acquiring fuel rods with high fuel duty values may be desirable to bound the worst case conditions of the fuel.

- Fuel Assembly Hardware. In general, irradiated fuel assembly hardware will not be available to the UFDC. However, if a full assembly of fuel is acquired for testing and placed in a SST, then grid spacers and end plates can be subjected to testing. Even then, the testing will be limited to a single alloy. Different fuel vendors use different materials for hardware (Zircaloy, Inconel ${ }^{\mathrm{TM}}$, stainless steel).

\section{FUNCTIONAL REQUIREMENTS FOR A SMALL-SCALE TEST}

Establishing the functional requirements for a small-scale test is important to ensure the test can meet its objectives. In this case, the test is to mimic long-term dry storage conditions for BWR HBU UNF so incite can be gained into any aging issues that might influence the long-term storage and ultimate handling of the fuel. The functional requirements needed to allow the test to achieve that goal are:

1) Representative BWR HBU fuel. The fuel should be as representative of the majority of BWR HBU UNF. It should not be lead test assemblies nor low-enriched fuel operated for additional cycles. The fuel should be from a normally operated reactor, run under normal conditions to achieve high burnup.

2) The fuel should be as free from external defects as possible. This will help reduce the chance for pre-existing conditions that might sway the test results. 
3) The test should utilize at least one fuel assembly. This ensures that not only fuel is involved in the test but also spacers, tie plates, water rods, etc. This also keeps many rods within a full field of radiation for the duration of the test. It should be noted that the Nuclear Regulatory Commission (NRC) in Interim Staff Guidance-24 (ISG-24) states in the Technical Review Guidance section, item 6: The demonstration program fuel shall include at least two full fuel assemblies. Therefore, if the small-scale test were to include two assemblies, it would be qualify as a demonstration under this NRC guidance. This point should be considered if a small-scale test is conducted.

4) The test should be vertical, if possible, so any potential vertical effects (such as potential creep) can occur. Horizontal would be acceptable as the NUHOMS systems store UNF horizontal, however, the potential for vertical creep cannot be addressed in such a test.

5) The test atmosphere is helium.

6) The test duration is ten years with an option to continue for longer periods of time.

7) The maximum temperature to be achieved by the furnace is $400^{\circ} \mathrm{C}$. This temperature is not expected, but provides a design maximum. The temperature control must allow a realistic temperature profile (i.e. similar to a commercial cask/canister) to be developed, including realistic cool-down rates.

8) It is desirable to have the fuel in the same condition that commercial fuel loaded into a large cask/canister is at a utility. The fuel will need to undergo a vacuum drying "heat treatment" at some point in time. The fuel must be dried for transport from a utility to a testing site. Likely, it makes most sense to dry the fuel for transport without altering the fuel cladding (heating the fuel in a manner to keep the fuel clad temperature below $65^{\circ} \mathrm{C}$ ). This will require a thermal analysis by the transport cask vendor to ensure this can be done. The fuel can be transported and subjected to a drying thermal cycle in the test system. This will ensure the slow cool down of the fuel can be accomplished by ramping down the furnace as a known rate to simulate the conditions of a storage cask or canister.

9) The vacuum drying thermal treatment is important, yet is somewhat unknown. There does not appear to be any thermal history data for commercial casks/canisters that have been dried using BWR fuel. A practical, and somewhat imperfect solution is to use data that will be obtained from the TN-32B cask that is being prepared for the PWR high burnup confirmatory data project. Once those data are obtained and the data checked by the thermal analysis team, a "best fit" can be made to the small-scale test system. The projected thermal treatment should be relevant and a realistic approximation to larger cask/canister systems.

10) The test system should allow for evaluating monitoring and testing instrumentation with the goal of gathering additional information from the test (e.g. fission gas, temperature profiles within an assembly) that might also be one day fitted to large commercial systems.

11) The test should be designed so it can be easily accessed. This means having a hotcell of other means to provide a radiologically safe way to access the fuel during the course of the test.

\section{FUEL FOR A SMALL-SCALE TEST}

\subsection{PWR Fuel Compared to BWR Fuel}

Generally, it is believed PWR UNF is bounding with respect to mechanical properties for storage and disposal for BWR UNF. Typically, PWR fuel cladding is generally thinner than BWR clad and PWR peak cladding temperatures are higher than BWR clad temperatures during operation.

However, as reactor fuel design has matured, BWR fuel cladding is becoming thinner due to the changes in assembly designs (more fuel rods of smaller diameter to aid in reduction of peak clad temperatures). BWR's tend to form a crud layer that is not as adherent and thicker than PWRs. This crud can influence 
the hydrogen uptake of the clad. The crud tends to cover more of the clad surface than PWRs, too. Further, BWR clad tends to be Zircaloy-2 and not niobium-containing alloys like AREVA M5 or Westinghouse Zirlo. Some BWR fuel venders have been adding thin, pure zirconium liners between the oxide fuel and the outer cladding layer. Some are adjusting their clad compositions to fit within the very edges of elemental composition ranges provided for Zircaloy-2 within ASTM International standards.

Structurally, a BWR assembly is often "held together" by special fuel rods that are threaded and used to hold the bottom plates onto the assembly. PWR assemblies use the guide tubes for this purpose and the load of the assembly never stresses the fuel.

\subsection{Typical Characteristics of BWR Fuel Assemblies}

There are numerous variations in BWR fuel assemblies. Three principle manufacturers compete in the U.S.; AREVA NP, Westinghouse, and Global Nuclear Fuels (GNF, comprised of GE, Toshiba and Hitachi). Fuel assembly designs have evolved from $7 \times 7$ fuel rod arrays to $11 \times 11$ arrays. At present, $10 \times 10$ fuel rod arrays are most common for high burnup service. 11x11 designs will replace those in the near future, but many of the designs are presently only in lead test assemblies and have not received full approval for use.

As the number of fuel rods in an assembly increases, a reduction in heat flux for a constant assembly power level results. Increasing the number of rods in an assembly also results in fuel rods of smaller diameter. This is due to the need to accommodate sufficient coolant flow across the fuel rod (maintaining sufficient rod-to-rod pitch). This has had another effect, to maintain more reactivity in a smaller diameter rod, the cladding has been made thinner. In a 10x10 assembly, BWR clad is about 0.026 inches $(0.66$ $\mathrm{mm})$ thick which is only 0.002 inches $(0.05 \mathrm{~mm})$ thicker than that of a typical $17 \times 17$ PWR assembly.

Another strategy to improve the heat flux is to employ part length fuel rods. Depending on the manufacturer, 12 or 14 part length rods are used. These rods serve to provide a space where the water vapor can exist separate from the surface of the cladding, thereby increasing the chance for liquid water on the upper surface of the full-length rods that are in the two-phase region of the fuel assembly.

In high burnup service, it was often believed BWR fuel tended to be a bit lower in burnup than PWR fuel. However, AREVA advertises their ATRIUM 10XP and XM series of fuel assemblies routinely reaching burnups to $66 \mathrm{GWD} / \mathrm{MTU}$ (in Europe), which is comparable to, if not higher than, most PWR designs. The other fuel vendors are reporting similar peak assembly burnups.

Historically, BWR fuel cladding has been Zircaloy-2. This alloy has excellent heat transfer characteristics as compared to other zirconium alloys. In the 1980s, in response to "pellet-clad interaction" failure issues, fuel vendors began adding a pure zirconium barrier to the inside of the fuel clad to absorb the force of the fuel pellets expanding during irradiation. In reality, the pellet-clad interaction issue turned out to be stress corrosion cracking due to iodine and cadmium. The use of linertype fuel cladding resulted in a major improvement in fuel reliability and effectively mitigated the pelletclad interaction failures. All vendors now offer fuel clad with some type of barrier/liner; AREVA is the one vendor that continues to offer fuel clad without a liner, although it is unknown how many utilities in the U.S. use unlined clad.

BWR fuel rods also experienced failure from debris fretting between fuel rods and grid spacers. Fuel vendors have work diligently to improve the filters located at the bottom tie plates to reduce the size of debris that can get into the fuel assembly and also improved cleanliness during fuel assembly manufacturer to eliminate the potential for debris being left behind. However, some debris related failures still occur. When a rod develops a small hole (from fretting), steam enters the rod and reacts with the inside surface of the clad and fuel. This can lead to hydriding of the fuel cladding from the inside of the rod and that can lead to embrittlement and a larger failure (e.g. due to stress caused by power ramping or simply power change). A pure zirconium liner/barrier layer had a lower corrosion resistance than the Zircaloy-2 outer cladding layer. The higher corrosion rate also led to the potential for large cracks due to 
the volumetric expansion as zirconium oxidizes. Experiments by fuel vendors led to another a modification to barrier layers; the addition of iron or tin to improve the corrosion performance of the barrier/liner layer. GNF has developed still another clad that has three layers, the outer Zircaloy-2, a middle layer of pure zirconium, and an inner layer of Zircaloy-2. The overall goal of all these efforts is to balance the need for pellet-clad interaction failure prevention with protection of the clad from debris fretting damage.

The fuel pellets used in BWRs have also evolved. Pellet end chamfering was introduced to help reduce fuel failures from stresses resulting from chipped pellets. Venders are also looking to reduce the opportunity for pellet-clad interactions by adding chromium or alumina-silica to the $\mathrm{UO}_{2}$ pellets. The goal is to reduce the amount of fuel rod creep rate, fuel pellet growth, fission gas release rate (e.g by trapping), and fuel pellet bonding to the cladding.

Fuel assembly "construction" is also a bit different that PWR fuel assemblies. In PWRs, the assembly guide tubes are used to join the top nozzle and bottom plate and the fuel rods are held in place by the grid spacers and simply rest on the bottom plate. BWR fuel assemblies produced by GNF or Westinghouse are held together differently. Some fuel rods are constructed to be "tie rods" that have threaded end fittings. These are threaded into the lower tie plate, and secured to the top plate by a threaded nut. These tie rods support the entire weight of the fuel assembly during handling. The remaining rods are held similarly to PWR assemblies. AREVA BWR fuel assemblies have evolved to the point where they join the top and bottom plates using the large central or offset water channel. No additional load is placed on any AREVA fuel rod in their fuel assembly design (e.g. ATRIUM series assemblies).

\subsection{Fuel Recommendations for a Small-Scale Test}

HBU BWR fuel assemblies of 10x10 design are most likely to be available with sufficient cooling to be useful for testing purposes. The fuel itself should be representative of the majority of fuel clad that is now available, namely a Zircaloy-2 clad with a zirconium liner ${ }^{d}$. Average assembly burnup should be above 50 GWD/MTU, but with average assembly discharges in the U.S. ranging from 45 to $52 \mathrm{GWD} / \mathrm{MTU}$, this might be a stretch goal. Partial fuel rods should be included.

The fuel assembly manufacturer (vendor) for a small-scale test is left undecided at this time. Acquisition of fuel for testing can be complicated and expensive. Ideally, a cooperative fuel vendor and utility are needed to successfully obtain a fuel assembly. Non-disclosure agreements are needed, transport casks arranged, fuel handlers must do the work, and there is necessarily a significant amount of management, oversight, planning, training, etc. that must occur at the utility. Those factors could impact the type of fuel that is available for a test.

The availability of fuel could impact the size of the test. With three large BWR fuel vendors in the U.S., a small-scale test could be sized from 1 to 3 fuel assemblies. If practical, it would be desired to include one assembly from each fuel vendor in the test. For the HBU Confirmatory Data Project using PWR fuel, the North Anna Power Station had used both Westinghouse and AREVA fuels in their operations. In this case, one utility could supply HBU UNF with four different cladding compositions. It would be desirable if one utility could supply more than one fuel vendor's BWR fuel types, but it is not known at this time if this possibility exists.

A test could still yield useful fuel performance and aging data even if it only included one fuel vendor's fuel. However, the variations in design, that could be important to handling fuel assemblies, such as tie rods versus water channel assembly support structures, could not be evaluated.

\footnotetext{
d It is recognized that in the future 11x11 assemblies may offer improved fuel clad such as Westinghouse's Zirlo clad, but as mentioned in section 1.3, most 11x11 fuel assemblies are many years away from being available in the U.S.
} 
Therefore, if only one fuel vendor's fuel is available, a small-scale test could be performed with any vendor's fuel with about the same overall test value regardless of vendor. If two fuel types are available, it would be preferred to have one AREVA fuel assembly (e.g. ATRIUM 10 series) that uses the water channel support structure and one Westinghouse (e.g. SVEA-96 series) or GE fuel assembly (e.g. GE14) that uses tie rods. If three assemblies can be acquired, then one assembly from each vendor should be obtained to allow the greatest understanding of the variations that fuel design could present to storage and transportation.

Fuels that might be obtained should be resident in reactor spent fuel pools with sufficient cooling time to allow loading into a dry storage system. This will also allow shipment using existing legal weight truck casks (e.g. the NAC-LWT or AREVA-TN TN-LC casks). This represents about 5 years cooling (or more) in the spent fuel pool which means any fuel assemblies being considered would have to be discharged around the year 2000, likely earlier. These fuels will not be the most modern fuels offered by each vendor, but they will be similar to and will have many of the design features being carried into the newer designs.

Since the early 1980s, Westinghouse has produced the SVEA ${ }^{\mathrm{e}}$ series of fuel assemblies. Likely candidates for small-scale testing are the SVEA-96 Optima and Optima2 designs. The Optima assemblies came into service in 1998 and Optima2 in 2000. These are both of a 10x10 fuel rod design utilizing a central water "cross" channel. Optima fuel assemblies have eight (8) 2/3-length fuel rods while Optima2 assemblies have those eight plus four (4) 1/3-length fuel rods located at the corners of the assembly.

There are 96 fuel rods total in the Westinghouse SVEA Optima series assemblies, arranged in four clusters of 24 rods. The fuel rod diameter can range from $9.62 \mathrm{~mm}$ to $10.3 \mathrm{~mm}$ depending on the utility requirements. In the early Optima series fuel, the cladding could be Zircaloy-2, but a ZrSn liner was available (and should be sought). The Optima 2 series fuels all came with the $\mathrm{ZrSn}$ liner alloy. The spacer girds are Inconel. There are 8 tie rods used in these assemblies.

Figure 3.1 is an illustration of the SVEA Optima2 style fuel assembly; the Optima series would be similar. Figure 3.2 is an illustration that highlights the fuel rod differences between the Optima and Optima2 assemblies. The differences include the addition of four 1/3-length fuel rods and the elimination of larger fuel rods near the centrally located part-length fuel rods.

The GE14 series of fuel assemblies were first introduced into service in the 1990s. It remains a current design of GE (GNF Global and GE Hitachi). The 10x10 fuel array contains 70 full-length fuel rods and 14 part length rods. The part length fuel rods are all slightly longer than $1 / 2$ of the full-length rods. The assembly is held together with 8 full-length tie rods located around the perimeter of the fuel assembly. The tie rods have threaded end fittings on both the top and bottom. The bottom is screwed into the lower tie plate while the upper is extends through the upper tie plate and is secured by a nut. There are two Zircaloy-2 circular water rods that extend through the assembly. Each rod displaces four fuel rods in the $10 \times 10$ array.

The GE14 clad is Zircaloy-2 and is available with a pure zirconium liner. The clad outer diameter is $10.26 \mathrm{~mm}$. The grid spacers are Zircaloy-4. Figure 3.3 provides an illustration of a GE14 fuel assembly. Figure 3.4 shows the locations of the water rods, tie rods, and partial rods in the assembly.

The AREVA ATRIUM 10 series of fuel assemblies were first introduced in 1992. The 10x10 fuel array can have a variety of configurations, but the 10XP and 10XM have 12 part length fuel rods and 79 fulllength fuel rods. The rod diameter is $10.28 \mathrm{~mm}$ for both assembly types. No tie rods are used in the AREVA assemblies; the assembly load is borne by the water channel that occupies the space of nine fuel rods. The Atrium 10XM series of assemblies are often provided with Zircaloy-2 clad fuel rods that have a $\mathrm{ZrFe}$ liner material. That makes the 10XM assemblies more desirable for testing than the 10XP series

\footnotetext{
e The term "SVEA" traces its roots to ASEA-ATOM in Sweden. However, what "SVEA" stands for appears lost in time.
} 
that have no liner. The spacer material is Inconel in both series of assemblies.

Figure 3.5 shows a cut-away illustration of a Atrium 10XM assembly without the full length fuel rods. Figure 3.6 is shows the location of the part length fuel rods in the various Atrium10 assemblies.

\subsection{Fuel Selection Summary Comments}

Acquisition of UNF for testing is neither simple nor inexpensive. It also can be an opportunistic process; that is, a potential source of fuel may come available that is a different type that discussed in section 3.3, but may be completely adequate for the test. Others might not have the ideal burnup or clad or some other feature hoped for. But, it is what can be obtained. It must be recognized that the recommendations of section 3.3 are merely that, recommendations. If a small-scale test were pursued, most likely a solicitation for sources sought would be posted to determine if there were interested vendors and utilities willing to provide fuel. That would lead to a discussion of what fuel is available, what costs could be expected to be incurred, and a potential schedule for acquisition. The fuel that could be obtained could vary from this report's recommendations, but the appropriate people will make those decisions at the appropriate time. 


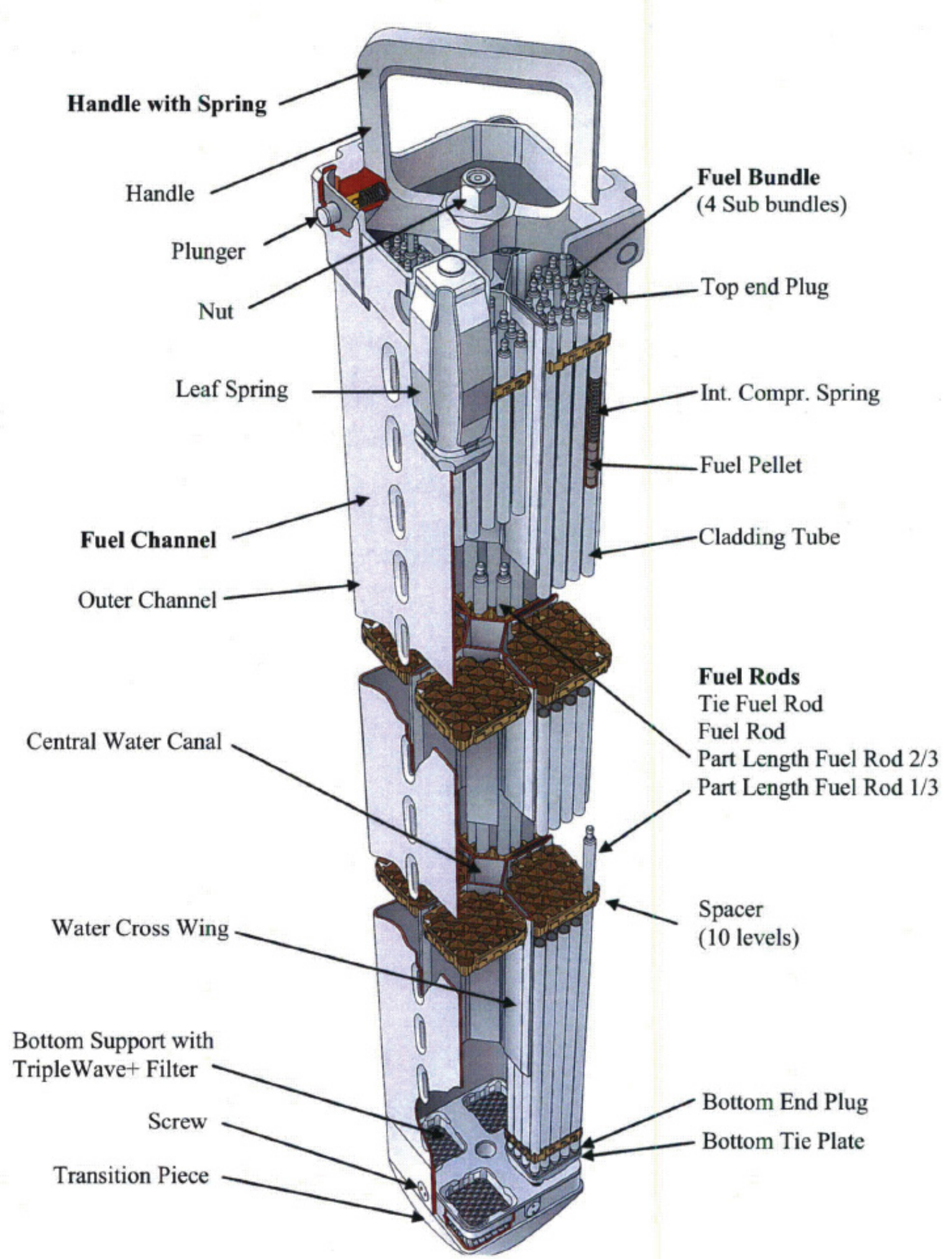

Figure 3.1. Westinghouse SVEA-style 10x10 fuel assembly. (Illustration courtesy of Westinghouse) 


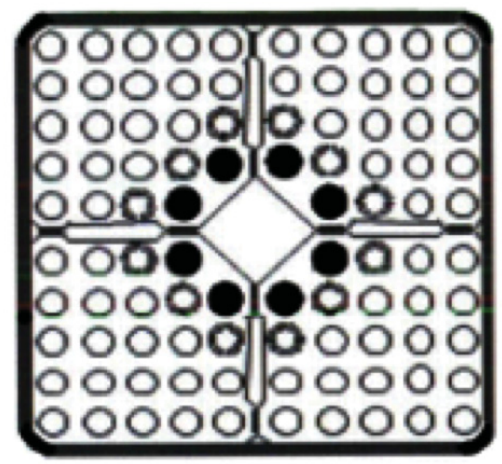

SVEA-96 Optima

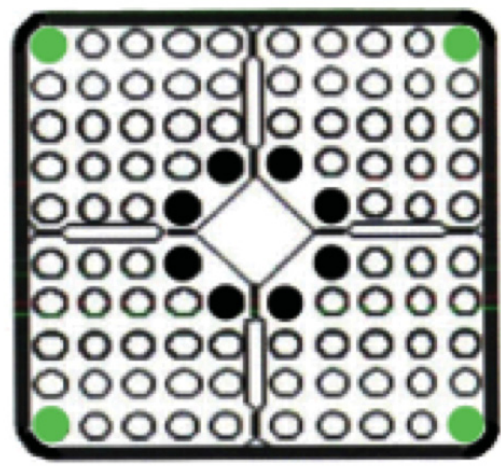

SVEA-96 Optima2

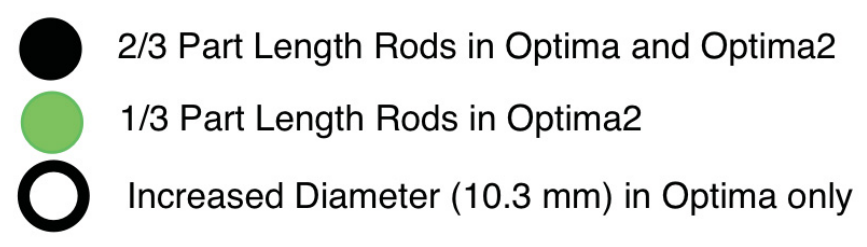

Figure 3.2. Westinghouse SVEA fuel assembly diagrams showing location of part-length rods and increased diameter rod in the earlier Optima series assemblies. (Illustration courtesy of Westinghouse) 


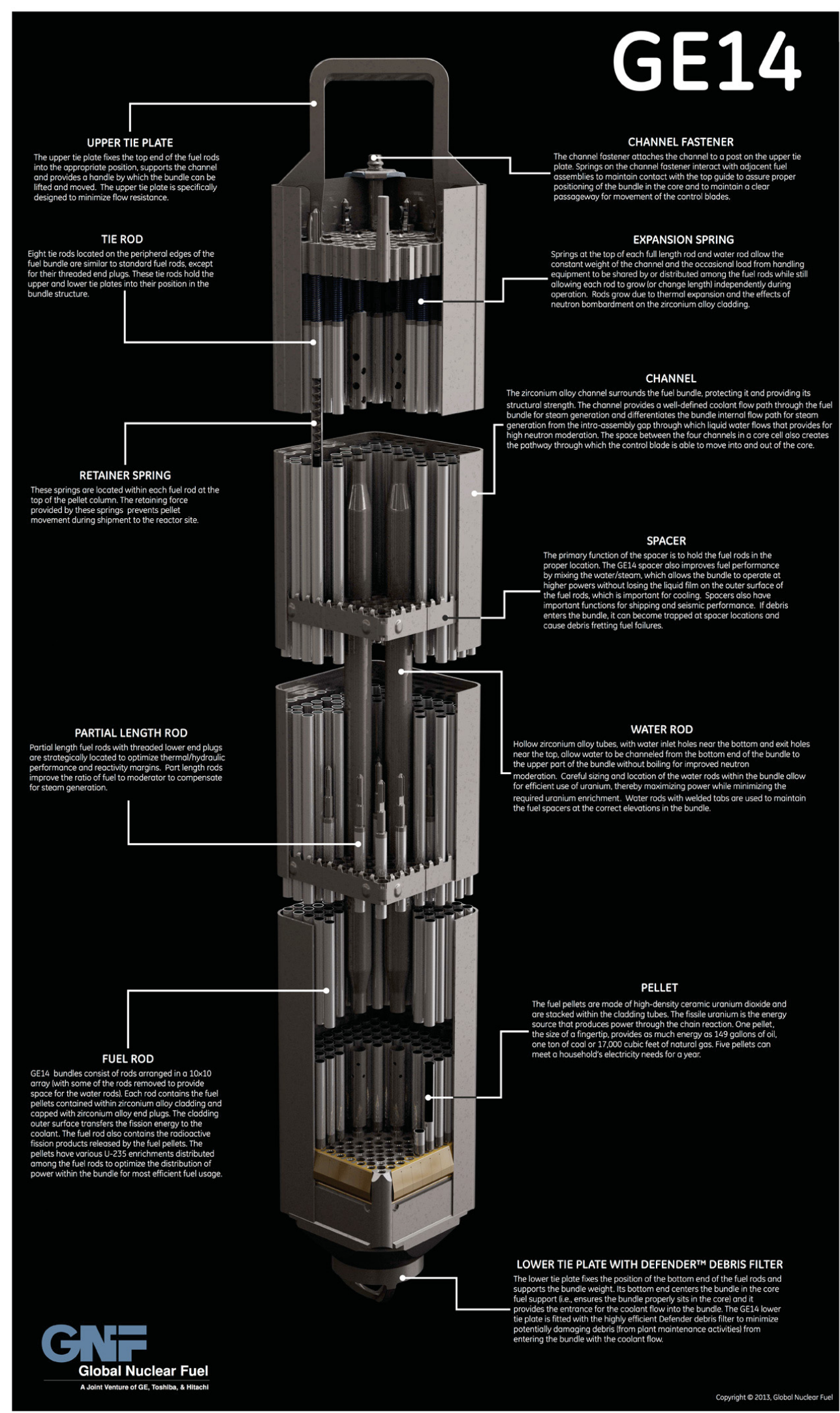

Figure 3.3. The GE14 fuel assembly is illustrated. (Illustration courtesy of GE-Hitachi) 


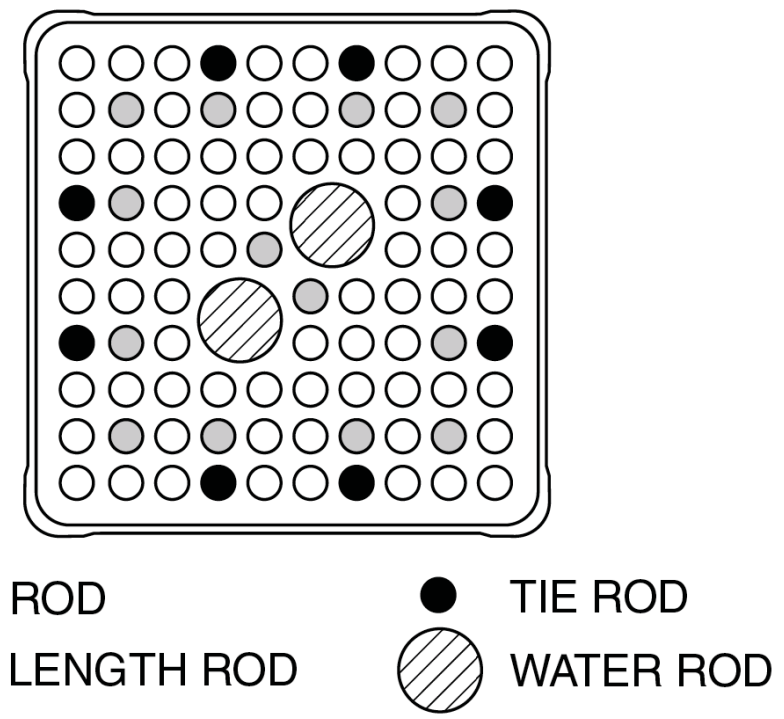

Figure 3.4. The GE14 assembly cross-section shows the locations of part-length rods, tie rods, and water rods. (Illustration courtesy of GE-Hitachi) 


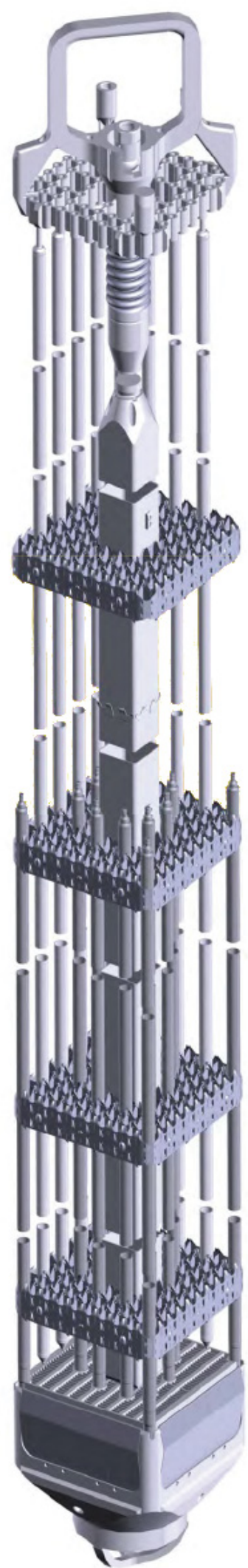

Figure 3.5. The AREVA ATRIUM 10XM 10x10 fuel assembly is shown without full-length fuel rods. (Illustration courtesy of AREVA, Inc.) 


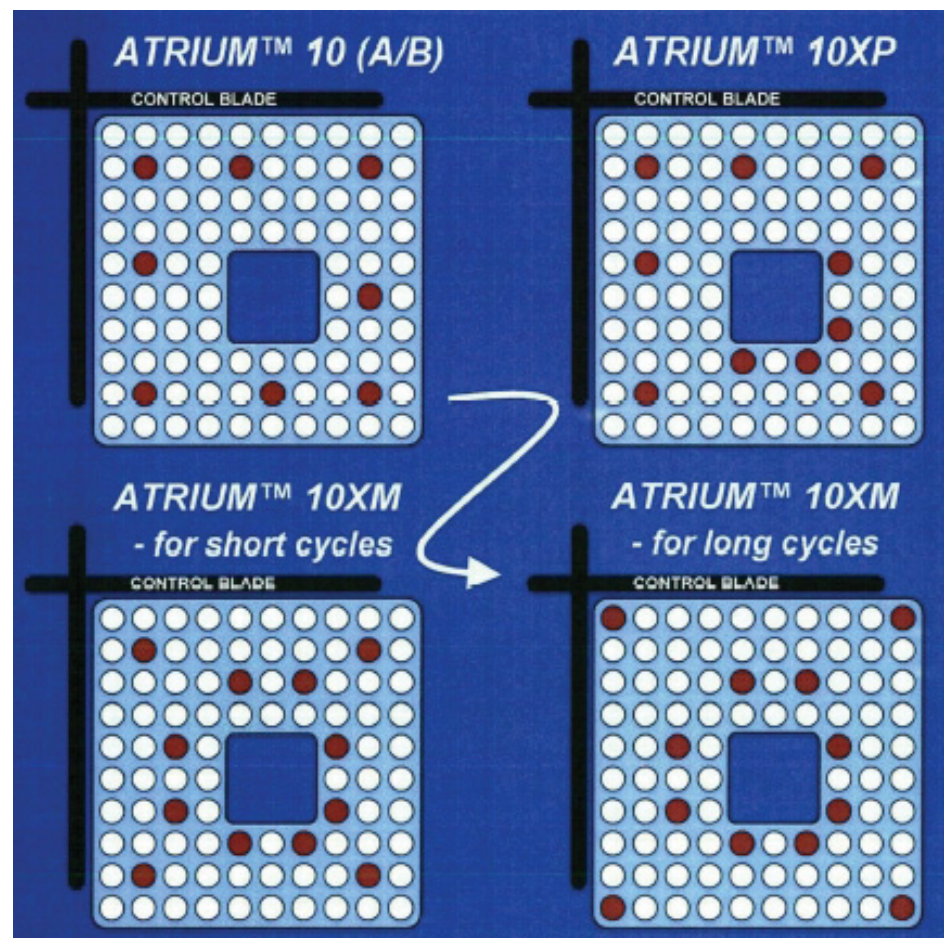

Figure 3.6. The AREVA ATRIUM-series fuel assembly cross-sections show the locations of part-length rods and the large water channel that is used to support the weight of the fuel assembly. (Illustration courtesy of AREVA, Inc.)

\section{CHARACTERIZATION AND TESTING}

\subsection{Initial Characterization}

Only one or two fuel rods would be removed from an assembly at the start of the test for initial characterization and testing. At most, in a 3-assembly test, a minimum of three rods and a maximum of six rods would be characterized and tested. A minimum of one rod will be pulled if the test uses only one assembly. These rods will be subjected to a series of characterization examinations and the characterized fuel will then be used in testing to determine the other properties of the fuel. The descriptions of the tests are in the following sections. Consistent with UFDC practice, the work is always driven to help support closure of technical data gaps that need to be filled to complete the mission of the campaign.

\subsection{Characterization}

The following sections provide detail on how the pulled fuel rods will be characterized. A fuel characterization campaign is segregated into non-destructive and destructive examinations. It is always advisable to conduct and complete as many non-destructive examinations as possible to have the needed data to inform where destructive examinations should be conducted. It is therefore recommended that each rod be subjected to non-destructive examination to establish its baseline condition, determine if there are any unexpected anomalies in the cladding, and determine if there are any indications of abnormal behavior of the fuel. It is important to note the logic of the examinations. Non-destructive examinations are some of the simplest and most cost-effective examinations that can be performed. They provide sufficient detail to begin planning the next step of the examinations. Each of those follow-on examinations is informed by the preceding examinations. For example, eddy current analysis, visual examination, and gamma scanning can be sufficient to plan where to section a rod for metallographic analysis. If it is desired to understand exactly where the fuel rod plenum is and where fuel-clad bonding begins, neutron radiography could be performed, but this is an optional test, after careful analysis of the 
gamma scan data. Rod puncturing to capture fission gas, determine the rod pressure, and allow determination of the rod free volume is strongly advised prior to cutting any rod. With only 3-6 rods, determination of the composition of the fuel (isotopics) and burnup are recommended to confirm utility calculated values.

\subsubsection{Non-Destructive Post-Irradiation Examination}

It is recommended the pulled rods be subjected to non-destructive PIE. This serves to document the condition of the fuel as it has been received and allows basic analyses to determine the condition of the clad, and the basic condition of the fuel inside the clad. These examinations also inform follow-on destructive examinations (e.g. where to section to obtain samples for subsequent analyses, if desired).

\subsubsection{Receipt Inspection}

Upon receipt, a gas sample will be taken from the shipping cask to determine if any fuel rods may have failed in transport. A gross rod failure (where the rod breaks in half) is not expected. A pinhole or crack might be possible that would release fission gas, and this would not change how the rods are handled. The facility will be prepared to deal with a gross failure should one happen. During unloading, a visual inspection of the assembly will be completed as the assembly is removed from the shipping cask. This visual exam will check for:

- Unexpected gross failures of a fuel rod during transport

- General appearance of the fuel assembly.

- Any other visual anomalies on the outer fuel rods surface that can be observed with the human eye through the hot cell window.

Of course, this infers the outer channel is removed from the assembly at the utility spent fuel pool.

\subsubsection{Visual Examination}

The pulled fuel rods will be subjected to a full length, high-resolution visual examination to document the as-received condition of the fuel and to serve for future reference. The examination needs to include the entire surface of the rods with a magnification of 1 to $10 \mathrm{X}$. This is done to provide a physical record of the fuel rods as-received condition that is complemented by the receipt inspection.

\subsubsection{Eddy Current Examination}

Eddy current examination is a technique that uses electromagnetic induction to conduct surface analysis on materials. Applied to zirconium-based nuclear fuel cladding, the technique can be used for the detection of surface defects (e.g. scratches, pits, cracks, holes) and to measure the thickness of surface oxide layers. The pulled fuel rods will be subjected to eddy current analysis for both defects and oxide layer thickness.

\subsubsection{Gamma Scanning}

Gamma scanning is used to determine the irradiated fuel location and pellet-pellet interfaces, relative isotopic concentrations, relative axial fuel-burn-up profiles, isotopic migrations, fuel dimensions, fission-gas generation, and other data to aid in evaluating the performance of irradiated fuels.

Of interest for UNF, these measurements are most useful for:

- Relative fuel burn-up and power profiles of a fuel rod

- Relative distribution of various isotopes in the fuel rod

- Identification of any fuel material relocation inside the cladding.

- Location of pellet-pellet interfaces

Two types of gamma scans are generally performed: 
- Gross gamma scans to determine the distribution of activity over the fuel rod's length

- Isotopic gamma scans to determine the isotopic distribution of activity over a fuel rod's length.

It is recommended all the pulled fuel rods be gamma scanned.

\subsubsection{Metrology}

Metrology documents the physical measurements of a fuel rod. This includes the profile (diameter and surface profile) and length of the fuel rod. This provides an indication of potential creep or growth of the fuel rod during irradiation and storage.

Often it is necessary to measure the bow of a fuel rod in order to calculate the actual length. It is not expected that significant bow will be seen. However, if the length of a fuel rod cannot be determined by simple measurement, bow measurement may be required.

The diameter of the fuel rod needs to be determined at several locations, continuously is preferred so a complete record of any swelling or other defect can be measured.

\subsubsection{Destructive Post-Irradiation Examination}

Destructive examination of fuel rods will only be performed once all needed non-destructive PIE is complete. Destructive examinations permanently change the characteristics of the fuel rod; for example, gas pressure is lost with the chance for in-leakage of unwanted gases into the fuel, fuel particles can fall out of cut segments of fuel resulting in unwanted contamination or loss of material, surface oxides/layers can be disturbed or destroyed during handling.

\subsubsection{Gas Pressure, Fission Gas Sampling, Free Volume Determination}

Commercial fuel rods are backfilled with helium gas in the range of 16-25 atmospheres pressure. The generation and release of fission gases during in-core performance may raise that pressure significantly. The overall fuel rod internal pressure is important because during the transition from wet storage in a spent fuel pool to dry storage in a used fuel cask/canister, it is this pressure that helps determine the resultant microstructure of the fuel clad and the orientation of zirconium hydrides.

Fission gas analysis provides a measure of isotopic composition of the gases found within a fuel rod. Combined with the free volume within a fuel rod, the number of moles of fission gas and helium can be calculated. This can also be used in verifying the percent of fission gas released from the fuel into the free volume of the fuel rod.

\subsubsection{Fuel Microstructure}

\section{Optical Microscopy}

Optical examinations are performed to examine the microstructure of the fuel and clad. These examinations can reveal information about the clad performance (e.g. hydrogen pickup, hydride formation and orientation, outer surface oxide/crud layer, inner fuel-clad interactions, swelling, and bambooing). The fuel meat can be examined for evidence of fracturing, swelling, fuel/clad bond delamination.

Optical metallography and ceramography begin by examination of the non-destructive data to select regions of interest for more detailed examination. Once a location on a fuel rod is selected, that region can be cut out of the fuel rod, mounted, polished, and treated as needed for visual examination. Optical images can be recorded reliably from low magnification up to about $750 \mathrm{X}$ with a light microscope in a hot cell. Higher magnifications can be achieved, but also require more work to obtain a properly prepared and flat surface for that examination.

\section{Electro-Optical Examinations (optional)}


Electro-optical examinations can be used to more carefully examine the fuel and clad. The achievable magnification and resolution are much higher allowing examination of features that might not be resolved using light microscopy.

Scanning electron microscopy (SEM) can be used to examine fuel and clad at magnifications well above 1000X. SEM is most useful when coupled with elemental analyses such as wavelength dispersive spectroscopy (WDS). Quantification methods for hydrides can be performed on SEMs with a little work.

One particular use for the SEM is the resolution and qualitative determination of the amount of radial and circumferential hydrides in a section of clad. Samples examined on a SEM can be performed under vacuum and the hydrides resolved without etching.

Transmission electron microscopy can be used to determine the crystallography of very small features/phases by electron diffraction, determine the microcracks or fine surface/oxide layers on phases, nucleation of species at grain boundaries, and examination of hydrides in clad. This will only be done as needed following SEM analyses.

\subsubsection{Radio-Analytical Chemistry}

Radio-analytical chemistry methods are used to determine the isotopic assay of the fuel, the quantity of fission products that diffuse into the clad, the amount of hydrogen in the clad, the composition of fission gases inside a fuel rod, the burn-up of fuel, linear heat generation rate, and more.

While many chemical analyses can be performed, this section focuses upon those analyses that should be performed to address data gaps important to UFDC.

Fission gas collected will be analyzed using a magnetic sector gas mass spectrometer.

There are multiple methods for determining the burn-up of a fuel rod. Burn-up determinations are typically done utilizing stable fission products. One method measures stable isotopes between ${ }^{85} \mathrm{Rb}-{ }^{154} \mathrm{Sm}$, another method measures the quantity of ${ }^{148} \mathrm{Nd}$ produced during irradiation.

The fuel isotopic mix of uranium, plutonium, curium, americium, and other elements is important to confirmation of models and other calculations (e.g., thermal analysis). Small segments of clad can be defueled, the fuel dissolved, and the elements and isotopes quantitatively analyzed.

Total hydrogen in the fuel clad is important to understanding the resultant mechanical properties of the clad. A "total combustion" type of instrument is often best for this purpose.

\subsubsection{Microchemistry}

There may be phases or features in the fuel and clad that investigators will want to examine more closely. There are semi-quantitative analytical tools that can be deployed for these purposes.

SEM with Wavelength Dispersive Spectroscopy (WDS) can be used to perform semi-quantitative analyses on microstructural features as small as a few microns. WDS can also be used to create element $\mathrm{X}$-ray compositional maps over a relatively broad area. These capabilities provide fundamental semiquantitative compositional information for features within a material.

Electron Probe Micro Analysis (EPMA) is used primarily for the non-destructive chemical analysis of very small solid samples. Though very similar to a SEM, the EPMA has multiple WDS instruments to provide increased accuracy of the analysis being conducted. Where a SEM with a single WDS can analyze spots of "several microns" in size, an EPMA can routinely quantitatively analyze spot sizes between 1 and 2 microns.

The EPMA could be useful for characterizing features such as the pellet-clad interface, high-burn-up pellet rim restructuring, and cladding degradation. 


\subsubsection{Other Properties}

\subsubsection{Micromechanical Testing}

The development of mechanical models for used fuel needs a detailed understanding of the strength of the various constituents of a HBU fuel rod. The fuel and the clad can be and have been characterized by traditional methods. However, HBU oxide fuels form a rim layer that is known to be somewhat porous yet hard. These fuels also form bond layers between the fuel and clad. A focused-ion beam (FIB) coupled with a pico-indenter can be used to mill small pillars of material in cross-sections of fuel rod samples and measure the compressive strength of these phases. This mechanical information can be used in the development of three-dimensional rod models that can be used in the analysis of overall fuel rod strength and response to loading (e.g. vibration, shock loading, cyclic loading).

\subsubsection{Mechanical Properties}

Mechanical properties include Young's modulus (modulus of elasticity), yield strength, ultimate yield strength, response to cyclic fatigue, and hardness. Within UFD, Ring Compression Tests (RCTs) have been used to obtain stress-strain data from fuel clad that yields the elastic modulus and strength. Cyclic Integrated Reversible-bending Fatigue Testing (CIRFT) has been used to determine the number of cycles to failure of a fuel sample under cyclic loading. The same test can also be used to derive stress-strain data. 4-point bending is another method that can be used to derive strength of fuel rods. Hardness is often evaluated by using samples mounted similar to metallography mounts to contain the material.

Microhardness testers can be used to gather hardness information on the cladding and fuel material.

\section{SMALL-SCALE TEST CONCEPT}

A small-scale test requires a considerable amount of space even though only 1-3 fuel assemblies are involved. The test needs to be radioactively shielded to protect workers from the high dose-rates associated with the fuel. The test will be long due to the assembly length $(\sim 173$ inches $/ 4400 \mathrm{~mm})$. Proposed methods for testing included:

- A large vessel constructed for installation inside a large, shielded hotcell.

- A shielded cask that can be placed at any suitable location.

There are advantages and disadvantages to both.

\subsection{Test Vessel In Hotcell}

This concept requires having a hotcell with sufficient vertical or horizontal space to house the test apparatus. Floor space within hotcells is typically limited, and a vertical test is desired over a horizontal test. In either case, the space needed in the long direction is a bit over twice the fuel assembly length to allow removal of fuel rods in the future. That length is about 30 feet $(9,150 \mathrm{~mm})$. At INL, the Hot Fuels Examination Facility (HFEF) was proposed due to the facility having two large, deep (30 feet) pits in the main hot cell. A test could potentially be located in one of these pits. However, with the restart of Transient Testing capability at INL, these pits are no longer available. Placing a test in a horizontal position in HFEF is impractical due to the other demands of programs on that space.

A horizontal test might be configured for the Oak Ridge National Laboratory (ORNL) Irradiated Fuels Examination Laboratory, (IFEL), or the Savannah River National Laboratory (SRNL) H Canyon reconfigurable hot cells. The horizontal test case is not evaluated in this report, primarily due to the inability to evaluate creep in a vertical direction. If this effect is deemed to be low priority or lesser importance to the performance of the fuel, then the horizontal test configuration should be evaluated.

\subsection{Shield Cask Out of Hotcell}

To conduct a small-scale test out of a hotcell, it must be housed in a vessel that can provide a nuclear safety envelop for the fuel and radioactive shielding. This is most easily achieved using a transportable 
cask. There are several casks available within the U.S. that could serve this purpose. Two such casks that have the size and shielding needed are the TN-FSV and NLI 1/2 casks.

The NAC International NLI $1 / 2$ transport cask was designed to reject up to $10.6 \mathrm{~kW}$. It had a capacity of 1 PWR or 2 BWR assemblies. The internal cavity is 13.375 inches $(340 \mathrm{~mm})$ in diameter by 178 inches $(4521 \mathrm{~mm})$ in length. The diameter is small enough that only two BWR assemblies could be fit in this cask while allowing room for heaters and instrumentation. These casks are the property of NAC International and would have to be leased or purchased for use by UFDC for a small-scale test.

INL owns two TN-FSV casks. These casks were constructed by Transnuclear, Inc. (now AREVA-TN) to transport the prismatic graphite fuels used in the Fort St. Vrain gas cooled reactor. The internal cask diameter is 18 inches $(457 \mathrm{~mm})$, and 199 inches $(5055 \mathrm{~mm})$ interior length. The casks were only designed to reject $0.36 \mathrm{~kW}$, but the cask could hold an assembly of PWR fuel up to $80 \mathrm{GWD} / \mathrm{MTU}$ cooled as short as 0.5 years. This cask could hold a three-assembly test and still have room for heaters and instrumentation. This cask is more suited for small-scale testing and is already owned by DOE. A photo of the cask is shown in Figure 5.1. The cross section of the cask is shown in Figure 5.2

A two-assembly concept is shown for the TN-FSV cask in Figure 5.3. This test proposes a stainless steel insert "basket" to hold the test. The heaters are shown as a wire wrap-style heater, but in reality, a multizone heating system will be required to achieve a representative cask/canister temperature profile from top to bottom. This test also shows the fuel assemblies with the channels still installed. The decision to leave or take these off would be made during the course of the thermal analysis that would accompany the final test design process.

The design is fitted with a radiation-hardened electrical plug in the lid to allow the basket to be sealed and allow all wiring (heater, instruments, thermocouples) to come through the lid. The basket can be loaded and the test assembled in the hotcell, then loaded into the cask. The basket can be purged with helium either in the hotcell or after loading into the cask (second option would need an approved filtered exhaust).

\subsection{Conduct the Test}

The process flow for a small-scale test would involve multiple steps.

- Conduct a survey to determine interest by utilities to supply fuel. That would be followed by procurement of the fuel. It is hoped a single utility might be able to supply BWR HBU UNF in different fuel vendor designs, but this might not be possible.

- The transport cask should be established. With the entry of the TN-LC into the U.S. market, this procurement would be made by competitive bid. The bid process should include a request to predict maximum fuel clad temperatures for a BWR HBU 10x10 fuel assembly. These data will be needed to determine the drying strategy for the fuel.

- The selected utility will need to procure the services of their fuel vendor(s) to handle and load the transport cask. Non-proprietary agreements will be needed to obtain needed data from the utility so the test thermal analysis can be conducted.

- The test basket design needs to be completed once the thermal analysis is complete.

- Once loaded, the fuel would be sent to the performing laboratory that will conduct the test.

- The fuel will be received and the assembly loaded into a hotcell.

- The process of handling, loading, transporting additional assemblies would then be completed as needed.

- One or two rods per assembly would be selected and removed for initial characterization. 
- The assembly or assemblies would be fitted with thermocouples to monitor the temperature of the test.

- The test would be fitted with gas sampling ports to allow sample and refill of the cask to the design helium overpressure.

- The test basket would be loaded with the fuel and sealed in the hotcell.

- At INL, the cask would be brought to the air hotcell at HFEF for helium leak checking. This could be done at other labs as well.

- Once the basket is sealed, it can be placed in the cask and electrical wiring checked.

- A modification to the cask lid would be made to allow the wiring to exit the cask.

- The cask would then be placed in a stand to initiate the test. At INL that could be inside the HFEF truck lock.

- The cask heating cycle would be initiated to start the test. It is hoped the heating cycle would be to replicate the thermal profile of a vacuum drying cycle. Then the cask would be allowed to follow a controlled cooling curve intended to replicate a full size commercial cask/canister.

- The cask should be gas sampled two three times in the first year to investigate the potential for fuel rod failure related to the initial "vacuum drying" thermal cycle. Following that, the cask might not be sampled but once per year or even less frequently if not fuel failures are detected from the initial heating.

Once the test has entered the cooling phase following attainment of the peak cask temperature following "drying," the test will enter routine operations. It will be necessary to monitor the thermal history of the cask to ensure the systems are properly operating and the cask is cooling as desired, but at this stage the test should operate nearly autonomously.

While these steps are greatly simplified, there are numerous large and small jobs needed to make the test successful. Those are captured in the budget numbers provided in Section 6. 


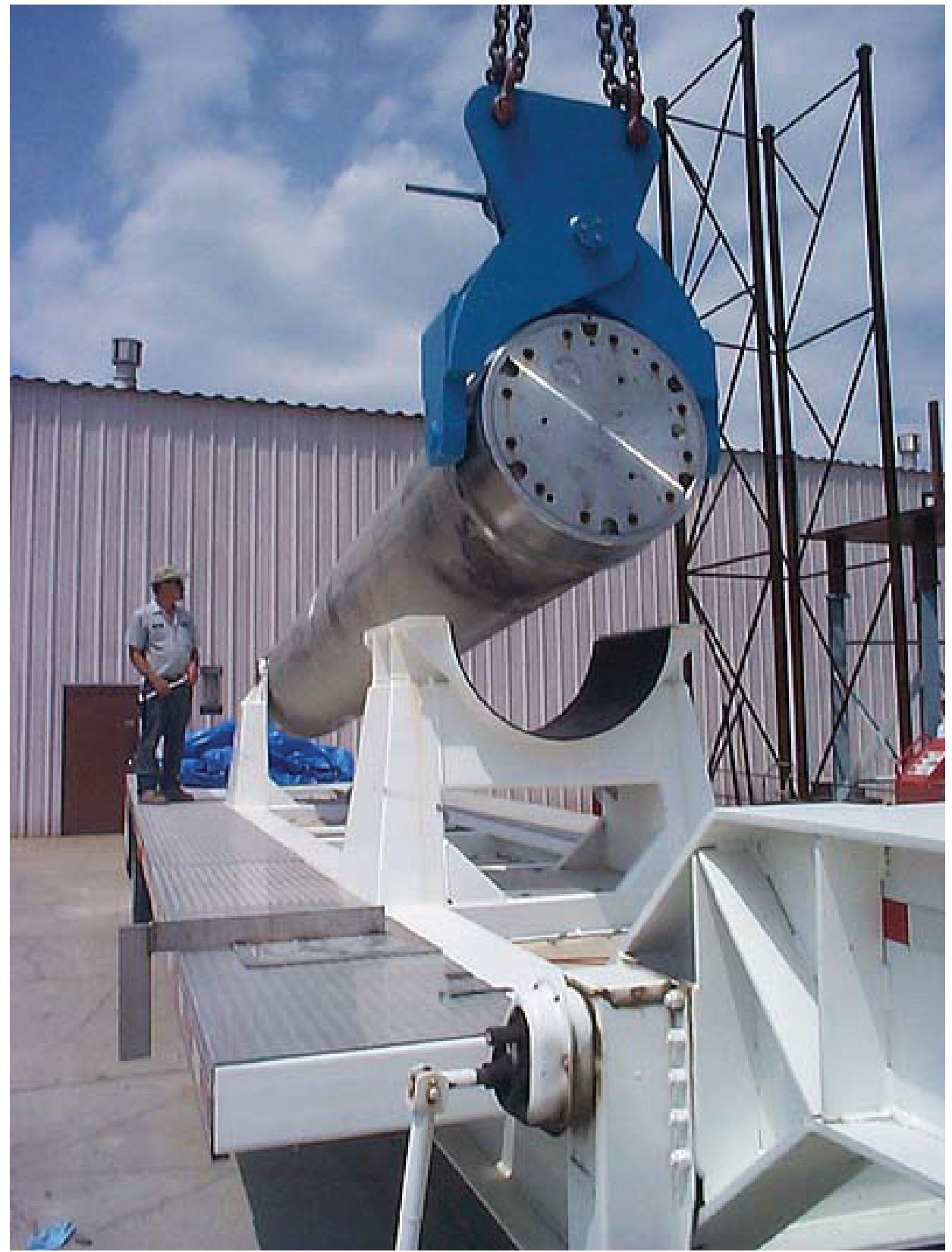

Figure 5.1. The TN-FSV cask being loaded onto its transport cradle.3.2.

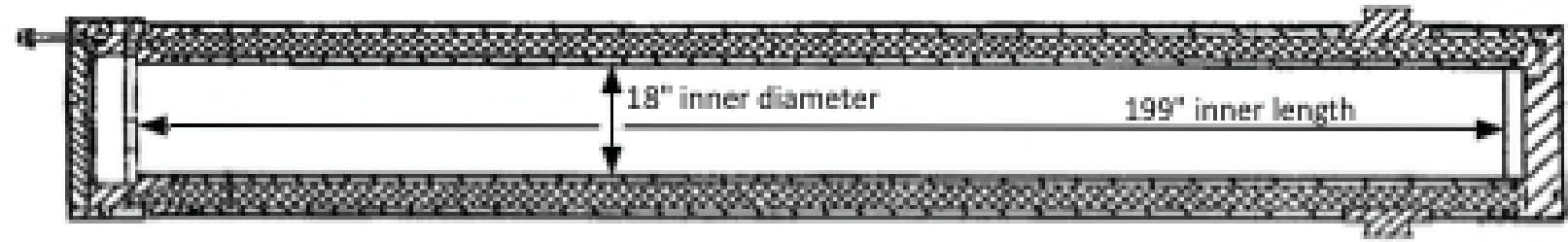

Figure 5.2. The TN-FSV illustrated in cross-section. The cask has one of the longest interior spaces of any legal weight transport cask. 


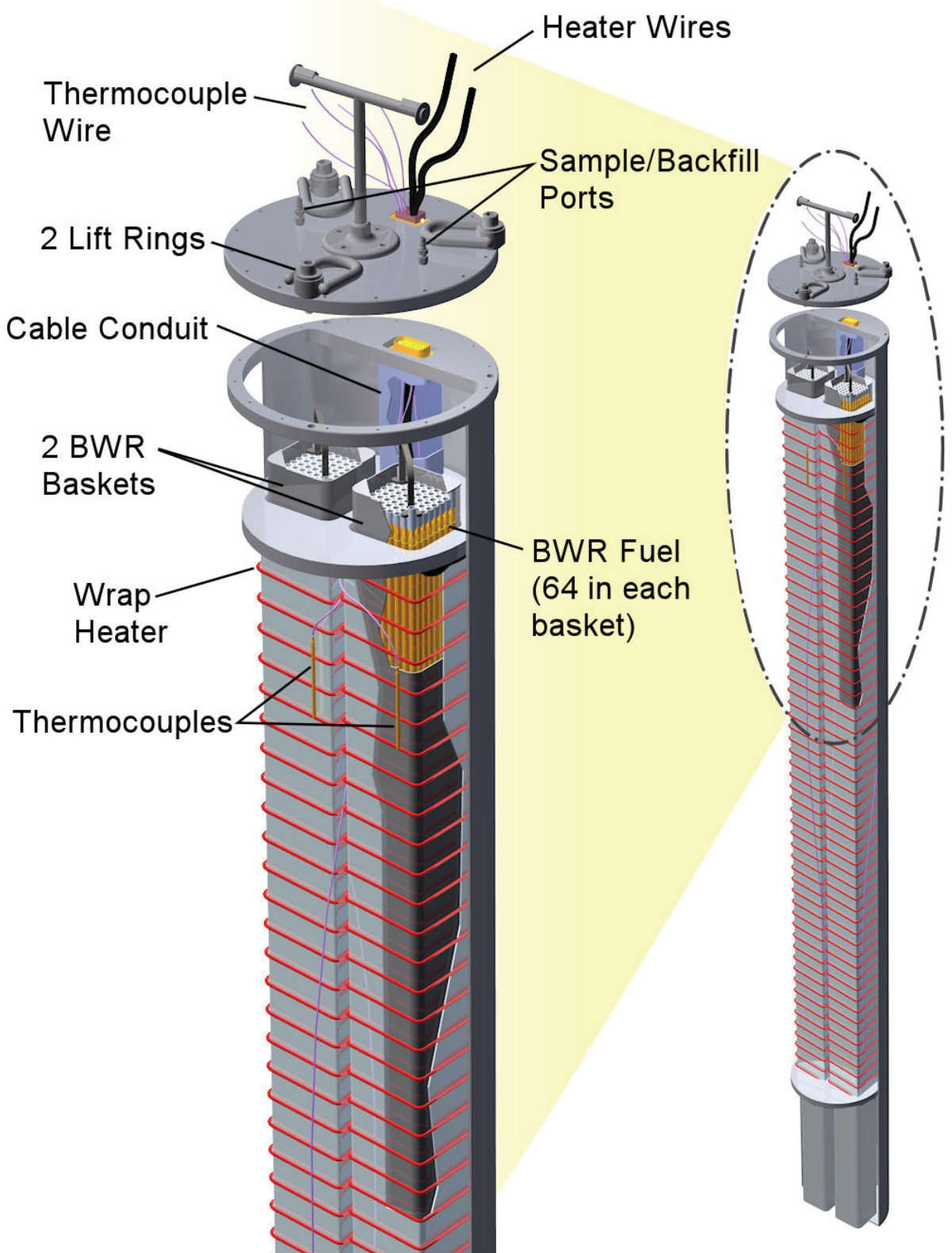

\section{CONCEPT FOR BWR CONTAINER HOLDING 2 BWR BASKETS}

Figure 5.3. Two-assembly test concept for the TN-FSV cask.

\section{COST ESTIMATE}

There are two principal cost categories; one time costs and recurring costs. This report deals principally with the initial set up of the test, initial characterization of the fuel, and annual operating costs. At this time UFDC does not have identified any data needs that would require the test to be opened for at least 10 years. If another program (or even UFDC) identifies a need to insert instrumentation, take gas samples, 
inspect fuel, or other intrusive activity, those are considered a separate project that would be estimated separately. Because the end-of-life timeframe for the test is so far into the future, those costs are not addressed here.

The cost estimate is detailed in Table 6.1. There is one large assumption in the estimate. It has been assumed one utility could supply more than one fuel vendor's fuel in their spent fuel pool with HBU characteristics. This possibility of this has not been explored (and explains the need for a solicitation of interest).

If a multiple-assembly test is desired, and fuel must come from two or three different utilities, the cost to acquire the fuel goes up significantly. For example, if two utilities are involved, it becomes necessary to rent the transport cask twice, pay two different utilities for labor, unload two separate shipments, etc. The cost adder is about $\$ 1400 \mathrm{~K}$ per additional utility. For example, if it is desired to have a two-assembly test and two utilities are needed to acquire the fuel, it is necessary to add $\$ 1400 \mathrm{~K}$ to the $\$ 4393 \mathrm{~K}$ estimate (for two assemblies shown in Table 6.1) for a total of $\$ 5783 \mathrm{~K}$. The cost for a three-assembly test using three utilities to supply the fuel would be $\$ 7538 \mathrm{~K}$. The initial fuel characterization would increase, as well, per the estimates in Table 6.1.

Individually costed items shown in Table 6.1 were developed from real-world experience were possible. The utility costs to supply fuel were derived from Dominion's costs to acquire PWR fuel at the North Anna Power Station for the HBU Confirmatory Data Project. Costs for renting and handling a transport cask come from the recent dry run conducted at INL by the Joint Fuel Cycle Studies program. Analytical laboratory costs associated with fuel characterization come from INLs Analytical Laboratory. The cost to evaluate the maximum temperature of used fuel during drying in a transport cask come from the actual cost to perform those calculations for the 25 sister rods from the HBU Confirmatory Data Project. Other costs were developed by working with facility managers and cost estimators at INL.

No waste disposal costs are shown in this estimate. Those costs are included in the analytical laboratory characterization costs. Disposal of LLW is incremental. Other waste steams are dependent upon the site where the test would be conducted. These costs could be substantial, particularly if any residual intact fuel rods or partial rodlets are deemed High Level Waste (HLW) and the testing site has no pathway for that waste. 


\begin{tabular}{|c|c|c|c|}
\hline Task & & Cost (\$K) & Notes \\
\hline \multicolumn{4}{|l|}{ One Time Costs } \\
\hline \multicolumn{4}{|c|}{ Fuel Acquisition } \\
\hline & Solicitation & 20 & \\
\hline & Negotiation & 20 & \\
\hline & $\begin{array}{l}\text { Utility/Vendor handling and } \\
\text { loading }\end{array}$ & 350 & Per fuel type \\
\hline & Utility Operations & 700 & \\
\hline & $\begin{array}{l}\text { Cask thermal analysis for } \\
\text { temperature upper limit of the } \\
\text { fuel }\end{array}$ & 45 & $\begin{array}{l}\text { Transport cask } \\
\text { vender supplied }\end{array}$ \\
\hline & Transport cask rental/shipping & 350 & \\
\hline & Cask receipt and unloading & 300 & \\
\hline & $\begin{array}{l}\text { Misc. support (travel, } \\
\text { oversight, supplies) }\end{array}$ & 100 & \\
\hline \multicolumn{4}{|l|}{ Test Vessel } \\
\hline & Cask cleaning and prep & 75 & \\
\hline & Cask stand fabrication & 150 & \\
\hline & Cask supplies (gaskets, bolts) & 5 & \\
\hline & Heater fabrication & 200 & \\
\hline & $\begin{array}{l}\text { Lid modification for test wiring, } \\
\text { gas sampling }\end{array}$ & 200 & \\
\hline & $\begin{array}{l}\text { Test insert (to hold assemblies } \\
\text { inside heater) }\end{array}$ & 150 & \\
\hline & Cask purge/fill/refill system & 100 & \\
\hline \multicolumn{4}{|c|}{ Test Instrumentation } \\
\hline & $\begin{array}{l}\text { Temperature measurement } \\
\text { (thermocouples or other) }\end{array}$ & 100 & \\
\hline \multicolumn{4}{|l|}{ Test Setup } \\
\hline & Inspect assemblies & 55 & per assembly \\
\hline & $\begin{array}{l}\text { Remove rods for pre-test } \\
\text { characterization ( } 2 \text { per } \\
\text { assembly) }\end{array}$ & 100 & per assembly \\
\hline & Cask handling in cell & 100 & \\
\hline & Assemble test in cask & 300 & \\
\hline & $\begin{array}{l}\text { Move cask to test location and } \\
\text { intiate test }\end{array}$ & 100 & \\
\hline & & 3520 & $\begin{array}{l}\text { Subtotal to set up } \\
\text { test }\end{array}$ \\
\hline \multirow[t]{4}{*}{ Contingency } & $15 \%$ & 528 & \\
\hline & & 4048 & $\begin{array}{l}\text { Subtotal with } \\
\text { contingency }\end{array}$ \\
\hline & & 4393 & $\begin{array}{l}\text { Subtotal with } \\
\text { contingency for } 2 \\
\text { assemblies }\end{array}$ \\
\hline & & 4738 & $\begin{array}{l}\text { Subtotal with } \\
\text { contingency for } 3 \\
\text { assemblies }\end{array}$ \\
\hline
\end{tabular}

Table 6.1 Cost estimate for a small-scale test in FY 2015 dollars 


\begin{tabular}{|c|c|c|c|}
\hline Task & & Cost (\$K) & Notes \\
\hline \multicolumn{4}{|l|}{$\begin{array}{l}\text { Initial Rod } \\
\text { Characterization }\end{array}$} \\
\hline & Visual, eddy current & 100 & per rod \\
\hline & Gamma Scan & 100 & per rod \\
\hline & Profilometry & 50 & per rod \\
\hline & $\begin{array}{l}\text { Rod puncture, gas pressure, } \\
\text { free volume }\end{array}$ & 100 & per rod \\
\hline & Fission gas analysis & 30 & per rod \\
\hline & Isotopics, burnup & 100 & per rod \\
\hline & Optical Microscopy & 100 & per rod \\
\hline & SEM/WDS & 75 & per rod \\
\hline & Mechanical Properties & 100 & per rod \\
\hline & & 755 & $\begin{array}{l}\text { Cost to } \\
\text { characterize one } \\
\text { fuel rod }\end{array}$ \\
\hline & & 1510 & $\begin{array}{l}2 \text { rods from } 1 \\
\text { assembly }\end{array}$ \\
\hline & & 3020 & $\begin{array}{l}4 \text { rods from } 2 \\
\text { assemblies }\end{array}$ \\
\hline & & 4530 & $\begin{array}{l}6 \text { rods from } 3 \\
\text { assemblies }\end{array}$ \\
\hline
\end{tabular}

\begin{tabular}{|l|l|r|l|}
\hline $\begin{array}{l}\text { Annual Operating } \\
\text { Costs }\end{array}$ & & & \\
\hline Project Management & & 150 & \\
\hline & Management, Admin & 75 & \\
\hline & QA & 50 & \\
\hline & Records & 10 & \\
\hline & Travel & & \\
\hline & & & \\
\hline $\begin{array}{l}\text { Facility annual } \\
\text { Operations }\end{array}$ & & 150 & \\
\hline & Facility Manager & 100 & \\
\hline & Technician/Operator & 75 & \\
\hline & RadCon & 50 & \\
\hline & Safety & & \\
\hline & & 660 & $\begin{array}{l}\text { Annual operating } \\
\text { cost }\end{array}$ \\
\hline & & & \\
\hline & & & \\
\hline
\end{tabular}

Table 6.1 continued

\section{Summary}

A small-scale test with BWR HBU UNF is possible, but the test will be expensive. The estimated cost to initiate a single assembly test is $\$ 5558 \mathrm{~K}$ (which includes the initial fuel characterization). This is the least expensive option; adding fuel from other vendors that might have to come from additional utilities raises the cost significantly. The annual operating cost for the test is estimated at $\$ 660 \mathrm{~K}$ (regardless of the number of assemblies in the test. These estimates are in FY 2015 dollars.

While expensive, this would be the only long-term storage test involving BWR UNF. BWR fuel has evolved to address failure issues associated with those reactor's fuels and those mechanisms are different from those found in PWRs. However, before embarking on a small-scale test, it would be prudent to explore alternate ways to gather information on BWR HBU UNF that might be more cost effective (e.g. international collaboration, separate effects testing). If a small-scale test is pursued, the test could serve as 
a test bed for new instrumentation that might benefit all of industry. That might bring other funding sources to the test, but would not offset the initial cost.

While establishing a test with fuel from three fuel vendors and having to involve three utilities would be the most expensive test, however, it would provide the greatest diversity of fuel and conditions. It would likely bracket the performance of most BWR HBU UNF in the U.S. thorugh the next 10 years or more (until the $11 \times 11$ assemblies with new cladding alloys are used in refueling or new starts).

\section{REFERENCES}

1. "High Burn-up Dry Storage Cask Research and Development Project: Final Test Plan." Contract No.: DE-NE-0000593 Electric Power Research Institute, Palo Alto, California., February 27, 2014

2. "Used Fuel Disposition Campaign - Gap Analysis to Support Extended Storage of Used Nuclear Fuel,” Revision 0, FCRD-USED-2011-000136 (PNNL-20509), Pacific Northwest National Laboratory, January 31, 2012

3. Used Fuel Disposition Campaign - Gap Prioritization and Closure Plan," Draft, FCRD-USED-2012000109, Pacific Northwest National Laboratory, April 30, 2012

4. "Used Nuclear Fuel Characteristics at End of Life," Revision 0, FCRD-UFD-2013-000130, March, 2013 